Mazur Karol, Machaj Dominik, Jastrzębska Sandra, Placzek Alicja, Mazur Dominika. Prediction of the development and susceptibility to acute mountain sickness (AMS) by monitoring oxygen saturation (SpO2) - literature review. Journal of Education, Health and Sport. 2020;10(2):79-84. eISSN 2391-8306. DOI http://dx.doi.org/10.12775/JEHS.2020.10.02.011 https://apcz.umk.pl/czasopisma/index.php/JEHS/article/view/JEHS.2020.10.02.011

https://zenodo.org/record/3665239

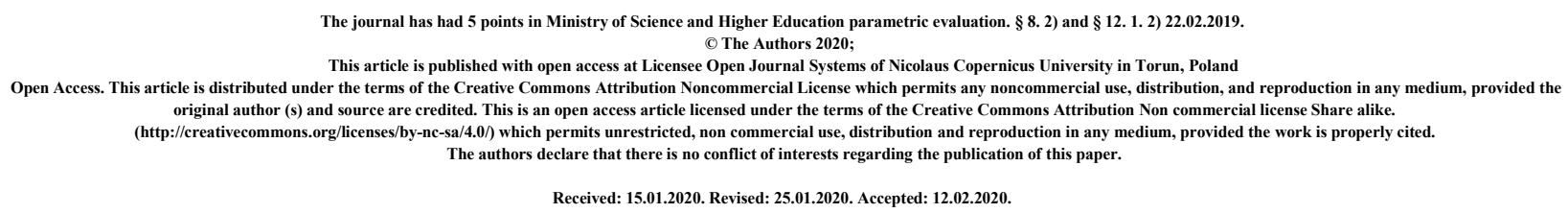

\title{
Prediction of the development and susceptibility to acute mountain sickness (AMS) by monitoring oxygen saturation (SpO2) - literature review
}

\author{
Karol Mazur, Dominik Machaj, Sandra Jastrzębska, Alicja Płaczek, Dominika Mazur
}

Karol Mazur, mazurkarol79@gmail.com, Faculty of Medicine, Medical University of Lublin, Chodźki Street 19, 20-093 Lublin, Poland Dominik Machaj, dominik5a4@tlen.pl, Faculty of Medicine, Medical University of Lublin, Chodźki Street 19, 20-093 Lublin, Poland

Sandra Jastrzębska, sandra0189@gmail.com, Faculty of Medicine, Medical University of Lublin, Chodźki Street 19, 20-093 Lublin, Poland

Alicja Płaczek, alicja60@poczta.onet.pl, Medical Faculty, University of Rzeszow, Pigonia Street 6, 35-310 Rzeszow, Poland

Dominika Mazur, dominika.hul20@gmail.com, Medical Faculty, University of Rzeszow, Pigonia Street 6, 35-310 Rzeszow, Poland

\section{Summary:}

The hypoxia is the main cause of altitude sickness, that usually starts from the benign form - acute mountain sickness (AMS), that being untreated can progress to the life-threatening states, like high altitude pulmonary edema (HAPE) and high altitude cerebral edema (HACE). The aim of this study was to evaluate the role of monitoring oxygen saturation in prediction of the of the development and susceptibility to acute mountain sickness (AMS). Our study material consisted of publications, which were found in PubMed, ResearchGate and Google Scholar databases. The first step was to find proper publications from the last 25 years . The second step was to carry out an overview of the found publications. Based on this criteria, six publications have been qualified for the study.

There is strong relationship between development and susceptibility to acute mountain sickness (AMS) and hypoxia. But this topic is not fully understood and needs to be better 
researched. Monitoring oxygen saturation could prevent from the development and predcit the susceptibility to AMS. Pulse oximetry could be also the indicator of adequate or inadequate acclimatization and high altitude performance

Key words: prediction, acute mountain sickness, AMS, oxygen saturation,

\section{INTRODUCTION AND PURPOSE}

People that try to rapid ascent to high altitude, typically above 2,500 metres $(8,000 \mathrm{ft})$ and that are not properly acclimatized and adapted, are exposed to the risk of the altitude sickness. The hypoxia is the main cause of altitude sickness, that usually starts from the benign form acute mountain sickness (AMS), that being untreated can progress to the life-threatening states, like high altitude pulmonary edema (HAPE) and high altitude cerebral edema (HACE) [1]. Because of that altitude sickness should be early recognized and treated aggressively. It is also very important to know the methods of preventions of the acute mountain sickness like proper acclimatization, administering acetazolamide and dexamethasone, or oxygen therapy [2]. Very helpful could be the knowledge about factors that may predict the risk of development or susceptibility of this disease [3].

Oxygen saturation ( $\mathrm{SpO} 2)$ is a measure of how much hemoglobin is currently bound to oxygen compared to how much hemoglobin remains unbound. Normal arterial blood oxygen saturation level ranges from $95 \%$ to $98 \%$. If the level is below 90 percent, it is considered low and called hypoxemia [4].

The aim of this study was to evaluate the role of monitoring oxygen saturation in prediction of the of the development and susceptibility to acute mountain sickness (AMS). Our study material consisted of publications, which were found in PubMed, ResearchGate and Google Scholar databases. In order to find the proper publications, the search has been conducted with the use of a combination of key words like: "prediction", "acute mountain sickness", "AMS", "oxygen saturation". The first step was to find proper publications from the last 25 years .The second step was to carry out an overview of the found publications. Based on this criteria, six publications have been qualified for the study. 


\section{DESCRIPTION OF THE STATE OF KNOWLEDGE}

\begin{tabular}{|c|c|c|}
\hline $\begin{array}{c}\text { Authors, tittle and year of } \\
\text { publication }\end{array}$ & Material and methods & Results \\
\hline $\begin{array}{l}\text { Roach R.C. et al., Arterial oxygen } \\
\text { saturation for prediction of acute } \\
\text { mountain sickness, } 1998\end{array}$ & $\begin{array}{l}102 \text { healthy asymptomatic climbers were } \\
\text { measured SpO2\% at } 4200 \mathrm{~m} \text { on Denali (Mt. } \\
\text { McKinley) prior to their further ascent toward } \\
\text { the summit at } 6194 \mathrm{~m} \text {, and on their return from } \\
\text { higher altitudes to } 4200 \mathrm{~m} \text {. Symptoms of the } \\
\text { acute mountain sickness (AMS) was assessed } \\
\text { with the Lake Louise Score (LLS). }\end{array}$ & $\begin{array}{l}\text { Resting arterial hypoxemia is related to } \\
\text { later development of clinical AMS, and can } \\
\text { exclude the occurrence and caution those at } \\
\text { risk for development of subsequent AMS. } \\
\text { Thus, non-invasive oximetry provides a } \\
\text { simple, specific indicator of inadequate } \\
\text { acclimatization to high altitudes and } \\
\text { impending AMS. }\end{array}$ \\
\hline $\begin{array}{l}\text { Tannheimer M. et al., Oxygen } \\
\text { saturation course and altitude } \\
\text { symptomatology during an } \\
\text { expedition to broad peak (8047 } \\
\text { m), } 2002\end{array}$ & $\begin{array}{l}\text { During ascent, base camp stay and approach to } \\
\text { the summit, oxygen saturation was measured } \\
\text { in the group of } 13 \text { mountaineers by pulse } \\
\text { oximetry at rest, during exercise and during } \\
\text { sleep. Symptoms of the acute mountain } \\
\text { sickness (AMS) was assessed with the Lake } \\
\text { Louise Score (LLS). }\end{array}$ & $\begin{array}{l}\text { Pulse oximetry is an objective non-invasive } \\
\text { method of measurement that is easy to } \\
\text { handle. It is a suitable device besides } \\
\text { clinical examination and questionnaire-test } \\
\text { in the diagnosis of high altitude illness } \\
\text { even in the hands of non-professionals. }\end{array}$ \\
\hline $\begin{array}{l}\text { Karinen H.M. et al., Prediction of } \\
\text { acute mountain sickness by } \\
\text { monitoring arterial oxygen } \\
\text { saturation during ascent, } 2010\end{array}$ & $\begin{array}{l}\text { There were measured oxygen saturation in the } \\
\text { group of } 74 \text { climbers at rest (R-SpO2) and } \\
\text { immediately after moderate daily exercise Ex- } \\
\mathrm{SpO} 2 \text { [50 m walking, target heart rate (HR) } \\
150 \mathrm{bpm} \text { ] at altitudes of } 2400 \text { to } 5300 \mathrm{~m} \text { during } \\
\text { ascent. Symptoms of the acute mountain } \\
\text { sickness (AMS) was assessed with the Lake } \\
\text { Louise Score (LLS). }\end{array}$ & $\begin{array}{l}\text { Those climbers who successfully maintain } \\
\text { their oxygen saturation at rest, especially } \\
\text { during exercise, most likely do not develop } \\
\text { AMS. }\end{array}$ \\
\hline $\begin{array}{l}\text { Faulhaber N. et al., Resting } \\
\text { arterial oxygen saturation and } \\
\text { breathing frequency as predictors } \\
\text { for acute mountain sickness } \\
\text { development: a prospective cohort } \\
\text { study, } 2014\end{array}$ & $\begin{array}{l}55 \text { persons were exposed to a simulated } \\
\text { altitude of } 4,500 \mathrm{~m} \text {. Cardio-respiratory } \\
\text { parameters, SpO2, blood lactate, and blood } \\
\text { pressure were measured after } 30 \text { min of } \\
\text { exposure. Symptoms of the acute mountain } \\
\text { sickness (AMS) was assessed with the Lake } \\
\text { Louise Score (LLS). }\end{array}$ & $\begin{array}{l}\text { Non-invasive measurements of } \mathrm{SpO} 2 \text { after } \\
30 \text {-min hypoxic exposure are easy to } \\
\text { perform and have the potential to detect } \\
\text { AMS-susceptible individuals with a } \\
\text { sufficient sensitivity. }\end{array}$ \\
\hline $\begin{array}{l}\text { Burtscher M. et al., Prediction of } \\
\text { susceptibility to acute mountain } \\
\text { sickness by SaO2 values during } \\
\text { short-term exposure to hypoxia, } \\
2004\end{array}$ & $\begin{array}{l}150 \text { healthy mountaineers that were classified } \\
\text { as susceptible to AMS (AMS+, } n=63 \text {,) and not } \\
\text { susceptible to AMS (AMS-, } n=87 \text {,) underwent } \\
\text { hypoxic exposure. SpO2 was measured after } \\
20 \text { to } 30 \text { min. Symptoms of the acute mountain } \\
\text { sickness (AMS) was assessed with the Lake } \\
\text { Louise Score (LLS). }\end{array}$ & $\begin{array}{l}\text { SpO2 values after } 20 \text { to } 30 \mathrm{~min} \text { of hypoxic } \\
\text { exposure be predictive for AMS } \\
\text { susceptibility. }\end{array}$ \\
\hline
\end{tabular}


Loeppky et al., Hypoxemia and Acute Mountain Sickness: Which Comes First?, 2008
51 persons underwent hypoxic exposure at a simulated altitude $4880 \mathrm{~m}$ with subsequent spirometry and gas exchange measurement. Symptoms of the acute mountain sickness (AMS) was assessed with the Lake Louise Score (LLS) and AMS-C Score.
Early desaturation is closely correlated with subsequent AMS. Early hypoxemia may be useful to predict AMS susceptibility.

The studies of Roach et al., Tannheimer et al. and Karinen et al. estabilished the role of monitroing oxygen saturation in prediction of the development of acute mountain sickness [5,6,7]. Roach et al. in their reserach measured SpO2\% in 102 healthy asymptomatic climbers at $4200 \mathrm{~m}$ on Denali (Mt. McKinley) prior to their further ascent toward the summit at $6194 \mathrm{~m}$, and on their return from higher altitudes to $4200 \mathrm{~m}$. The results showed that resting arterial hypoxemia is related to later development of clinical AMS, and can exclude the occurrence and caution those at risk for development of subsequent AMS. Therefore this study estabilished non-invasive oximetry as a simple, specific indicator of inadequate acclimatization to high altitudes and impending AMS [5]. Tannheimer et al. in their research measured oxygen saturation in climbers by pulse oximetry at rest, during exercise and sleep in time of ascent, base camp stay and approach to the summit. The results revealed significant between measured oxygen saturation during ascent to high altitude and acute mountain sickness, as well as with high altitude performance. Thank to that this study confirmed that monitoring oxygen saturation may allow to predict the occurrence of AMS [6]. Karinen et al. measured R-SpO2 and Ex-SpO2 in climbers after moderate daily exercise at altitudes of 2400 to $5300 \mathrm{~m}$ during ascent. The results showed that R-SpO2 was lower at all altitudes among those climbers suffering from AMS during the expeditions than among those climbers who did not get AMS at any altitude during the expeditions. Thus this research proved that those climbers who successfully maintain their oxygen saturation at rest, especially during exercise, most likely do not develop AMS. Thanks to that daily evaluation of $\mathrm{SpO} 2$ during ascent both at rest and during exercise can help to identify a population that does well at altitude [7].

The studies of Faulhaber et al., Burtscher et al. and Loeppky et al. showed that monitoring oxygen saturation may help in detection the susceptibility to acute mountain sickness $[8,9,10]$. In the Faulhaber et al. research $\mathrm{SpO} 2$ values of AMS-susceptible individuals were significantly 
lower after $30 \mathrm{~min}$ of hypoxic exposure than AMS- not susceptible [8]. Burtscher et al. evaluated the relationship between arterial oxygen saturation after a 20- to 30-min exposure to hypoxia and the susceptibility to AMS. The results of their research showed that SpO2 values after 20 to 30 min of hypoxia were on average $4.9 \%$ lower in AMS+ than in AMS-. Therefore they confirmed that $\mathrm{SpO} 2$ values measured after 20 to 30 min of hypoxic exposure are good predictors of AMS susceptibility [9]. Loeppky et al. evaluated the relationship between AMS and hypoxemia. The result of this study revealed that subjects who proved susceptible to AMS within 8 to $12 \mathrm{~h}$ at simulated altitude had significantly greater hypoxemia after $1 \mathrm{~h}$ of exposure than those who do not become ill. Thanks to that they proved that early desaturation is closely correlated with subsequent AMS it may be useful to predict AMS susceptibility [10].

According to the cited research, there is strong relationship between development and susceptibility to acute mountain sickness (AMS) and hypoxia. But this topic is not fully understood and needs to be better researched. Monitoring oxygen saturation could prevent from the development and predict the susceptibility to AMS. Pulse oximetry could be also the indicator of adequate or inadequate acclimatization and high altitude performance. This non-invasive method of measurement could increase chances of summit success.

\section{CONCLUSIONS}

1. The hypoxia is the main cause of altitude sickness (AMS).

2. There is strong relationship between development and susceptibility to acute mountain sickness (AMS) and hypoxia. But this topic is not fully understood and needs to be better researched.

3. Monitoring oxygen saturation could prevent from the development and predcit the susceptibility to AMS.

4. Pulse oxymetry could be also the indicator of adequate or inadequate acclimatization and high altitude performance 


\section{LIST OF REFERENCES:}

1. Hackett P.H., Roach, R.C. High-altitude illness. N Engl J Med. 2001; 345: 107-114.

2. Hackett, P.H., Rennie, D., and Levine, H.D. The incidence, importance, and prophylaxis of acute mountain sickness. Lancet. 1976; 2: 1149-1155.

3. Luks, A.M., McIntosh, S.E., Grissom, C.K., Auerbach, P.S., Rodway, G.W., Schoene, R.B. et al. Wilderness Medical Society Practice Guidelines for the prevention and treatment of acute altitude illness: 2014 update. Wilderness Environ Med. 2014; 25: S4-S14.

4. Hafen B.B.,Sharma S.,Oxygen Saturation. 2019; StatPearls Publishing.

5. Roach, R.C., Greene, E.R., Schoene, R.B., and Hackett, P.H. Arterial oxygen saturation for prediction of acute mountain sickness. Aviat Space Environ Med. 1998; 69: 1182-1185.

6. Tannheimer, M., Thomas, A., and Gerngross, H. Oxygen saturation course and altitude symptomatology during an expedition to Broad Peak (8047 m). Int J Sports Med. 2002; 23: 329-335.

7. Karinen H.M., Peltonen J.E., Kahonen M., and Tikkanen H.O. Prediction of acute mountain sickness by monitoring arterial oxygen saturation during ascent. 2010; High Alt Med Biol 11:325-332.

8. Faulhaber M., Wille M., Gatterer H., Heinrich D., Burtscher M. Resting arterial oxygen saturation and breathing frequency as predictors for acute mountain sickness development: A prospective cohort study. 2014; Sleep Breath 18:669-674.

9. Burtscher M., Flatz M., Faulhaber M. Prediction of susceptibility to acute mountain sickness by $\mathrm{SaO} 2$ values during short-term exposure to hypoxia. 2004; High Alt Med Biol 5:335-340.

10. Loeppky, J.A., Icenogle, M.V., Charlton, G.A. et al. Hypoxemia and acute mountain sickness: which comes first?. High Alt Med Biol. 2008; 9: 271-279. 